\title{
Progression of diabetic retinopathy after cataract extraction
}

\author{
Ayala Pollack, Shlomo Dotan, Moshe Oliver
}

\begin{abstract}
The course of diabetic retinopathy following cataract extraction was studied retrospectively in 89 patients (89 eyes). Cataract extraction was extracapsular in 12 eyes (13.5\%), extracapsular with intraocular lens implantation in $37(41.6 \%)$, and intracapsular in $40(45 \%)$. In 55 eyes $(61.8 \%)$ there was no change in the retinal status after surgery, and in $34(38 \cdot 2 \%)$ there was progression of diabetic retinopathy. In the eyes showing progression there was appearance or aggravation of non-proliferative changes in $85.3 \%$ and development of proliferative diabetic retinopathy in $14.7 \%$. Most of these eyes $(91 \%)$ deteriorated within six months of surgery. Risk factors for the progression of diabetic retinopathy were the preoperative existence of diabetic retinopathy $p<0.005)$ and the need for antidiabetic agents in addition to dietary control in the management of diabetes $(p<0 \cdot 025)$.
\end{abstract}

Diabetes mellitus occurs in an estimated $2 \cdot 3 \%$ of the population in the United States. ${ }^{1}$ This means that the number of diabetic patients undergoing cataract surgery every year is relatively large and is expected to increase even further with the gradual rise in life expectancy of diabetic patients owing to improved medical management.

The effect of cataract surgery on the postoperative course of diabetic retinopathy is unclear. Jaffe and Burton ${ }^{2}$ reported the development of a severe exudative form of diabetic macular oedema following cataract extraction. We have recently described the pattern of deterioration of diabetic retinopathy after cataract surgery. ${ }^{3}$ Other authors ${ }^{46}$ have also described postoperative progression of diabetic retinopathy resulting in poor vision. In contrast, Sebestyen $^{7}$ found that cataract surgery was not associated with the progression of diabetic retinopathy, as in his series of patients similar progression was observed also in the unoperated fellow eye.

The purpose of this retrospective study was to examine the relationship between cataract surgery and the postoperative course of diabetic retinopathy.

\section{Department, Kaplan}

Hospital, Rehovot, affiliated with the Hebrew University-Hadassah Medical School, Jerusalem, Israel A Pollock S Dotan

M Oliver

Correspondence to:

A Pollack, MD

Ophthalmology Department,

Kaplan Hospital, 76100

Rehovot, Israel.

Accepted for publication

8 March 1991 89 patients who met the following criteria: (1) diabetes mellitus diagnosed at least six months prior to cataract surgery; (2) uneventful surgical procedure, with no vitreous loss or rupture of posterior lens capsule; (3) no laser treatment for established diabetic retinopathy applied either before surgery or within one month after surgery; (4) no other ocular disorders; (5) a postoperative follow-up period of at least one year; (6) a fundal examination prior to or within three days after surgery which served as a baseline examination for further comparison of the postoperative retinal course; and (7) additional fundal examinations during each of three distinct periods within the first year of follow-up. The first of these follow-up periods, F1, was from the beginning of the second week after surgery to the end of the third month. The second, F2, was between four and six months after surgery, and the third, F3, was between the seventh and the twelfth month.

For each patient a standardised medical protocol was completed, giving detailed demographic and clinical information including duration of diabetes mellitus, presence of other systemic diseases, and types of medication. The findings of the baseline ocular examination as well as those of each follow-up period were recorded. The examinations included best corrected visual acuity; applanation tonometry, biomicroscopy, Goldmann three-mirror examination, and indirect ophthalmoscopy. Also recorded were the findings of colour fundus photographs and of fluorescein angiography and the results of laser treatment applied during the follow-up periods. Laser treatment consisted of panretinal photocoagulation for proliferative or severe nonproliferative diabetic retinopathy and/or focal or grid argon green laser photocoagulation for macular oedema. ${ }^{8-11}$

On the basis of the ocular findings two subgroups were identified. The first, defined as the 'no change' subgroup, consisted of eyes in which the retinal status remained unchanged following surgery regardless of whether diabetic retinopathy was present preoperatively. The second, termed the 'progression' subgroup, consisted of eyes in which diabetic retinopathy progressed following surgery. Progression was considered to have occurred either when (1) a patient with no pre-existing diabetic retinopathy (NoDR) developed either non-proliferative (NPDR) or proliferative diabetic retinopathy (PDR) after surgery; or (2) a patient with pre-existing NPDR showed either postoperative aggravation of the non-proliferative changes or development of PDR, as we have previously described. ${ }^{3}$

Three surgical techniques were employed. Intracapsular cataract extraction (ICCE) was performed between 1977 and 1980, and extracapsular cataract extraction (ECCE) or extracapsular cataract extraction with intraocular lens implantation (ECCE with IOL) between 1980 and 1986. During 1979-80 there was a period of 
Table 1 Comparison of clinical features in study group and controls

\begin{tabular}{|c|c|c|c|c|c|}
\hline & \multicolumn{2}{|l|}{ Operated patients } & \multirow[b]{2}{*}{$p$} & \multicolumn{2}{|l|}{ Non-operated patients } \\
\hline & $\begin{array}{l}\text { No change (55 cases) } \\
(61 \cdot 8 \%)\end{array}$ & $\begin{array}{l}\text { Progression ( } 34 \text { cases) } \\
(38 \cdot 2 \%)\end{array}$ & & $\begin{array}{l}\text { No change (61 cases) } \\
(87 \cdot 2 \%)\end{array}$ & $\begin{array}{l}\text { Progression ( } 9 \text { cases) } \\
(12 \cdot 8 \%)\end{array}$ \\
\hline Mean age, yr (range) & $67 \cdot 7, \operatorname{SD} 8(45-58)$ & $66 \cdot 5$, SD $7(49-77)$ & & $63 \cdot 1, \operatorname{SD} 7(45-79)$ & $61 \cdot 4$, SD $6(45-80)$ \\
\hline $\begin{array}{l}\text { Mean duration of DM, yr } \\
\text { (range) }\end{array}$ & $10 \cdot 9, \operatorname{SD} 9(0 \cdot 5-30)$ & $9 \cdot 4$, SD $6(1 \cdot 5-28)$ & & $10, \operatorname{SD} 9(0 \cdot 5-30)$ & $11 \cdot 1$, SD $7(1-30)$ \\
\hline $\begin{array}{l}\text { No. of patients }(\%) \\
\text { Male:female }\end{array}$ & $23: 32(41: 58)$ & $16: 18(47: 53)$ & & $24: 37(39: 61)$ & $3: 6(33: 67)$ \\
\hline $\begin{array}{l}\text { Management of DM: } \\
\text { Diet alone } \\
\text { Hypoglycaemic agents } \\
\text { Insulin }\end{array}$ & $\begin{array}{l}12(22) \\
33(60) \\
10(18)\end{array}$ & $\begin{array}{c}1(3) \\
24(71) \\
9(26)\end{array}$ & $<0.025$ & $\begin{array}{c}5(8) \\
32(53) \\
24(39)\end{array}$ & $\begin{array}{l}- \\
4(44) \\
5(56)\end{array}$ \\
\hline $\begin{array}{l}\text { Vascular disease: } \\
\text { Hypertension } \\
\text { Cardiac } \\
\text { Other diseases: }\end{array}$ & $\begin{array}{l}22(47) \\
6(13) \\
2(3 \cdot 6)\end{array}$ & $\begin{array}{c}12(40) \\
4(13) \\
3(9)\end{array}$ & & $\begin{array}{c}16(26) \\
3(5) \\
1(1 \cdot 6)\end{array}$ & $\begin{array}{l}5(56) \\
1(11) \\
-\end{array}$ \\
\hline
\end{tabular}

$\mathrm{DM}=$ diabetes mellitus.

transition from the ICCE to the ECCE technique, when both procedures were used. In the earlier ECCE procedures IOL implantation was not performed because of our lack of experience with IOLs in diabetic eyes. All operations were performed by senior surgeons specialised in anterior chamber surgery. Fundal examinations, colour fundus photographs, and fluorescein angiography readings were performed by retinal specialists.

The control group consisted of 70 diabetic patients who had been admitted to our retina clinic for evaluation of their diabetic retinopathy status and were not operated on. Inclusion criteria were (1) completion of the same standardised medical protocol as the study group, described above; (2) diabetes mellitus diagnosed at least six months prior to the initial evaluation; (3) no prior laser treatment for established diabetic retinopathy; (4) no laser treatment for diabetic retinopathy performed either immediately or within one month following the initial examination; (5) no other ocular disorders; (6) a follow-up period of at least one year; and (7) at least three fundal examinations, F1, F2, F3, as described above for the study group.

The $\chi^{2}$ test was used for statistical analysis.

Table 2 Postoperative progression of diabetic retinopathy in relation to the surgical technique (numbers of eyes with percentages in parentheses)

\begin{tabular}{|c|c|c|c|c|}
\hline Course of $D R$ & $\begin{array}{l}E C C E \\
\text { (8 eyes) }\end{array}$ & $\begin{array}{l}\text { ECCE with } I O L \\
\text { (10 eyes) }\end{array}$ & $\begin{array}{l}\text { ICCE } \\
\text { (16 eyes) }\end{array}$ & $\begin{array}{l}\text { Total } \\
\text { (34 eyes) }\end{array}$ \\
\hline $\begin{array}{l}\text { From NoDR to NPDR } \\
\text { Aggravation of NPDR } \\
\text { Subtotal NPDR: }\end{array}$ & $\begin{array}{l}2(25) \\
5(62 \cdot 5)\end{array}$ & $\begin{array}{l}3(30) \\
6(60)\end{array}$ & $\begin{array}{c}3(18 \cdot 75) \\
10(62 \cdot 5)\end{array}$ & $\begin{array}{r}8(23 \cdot 5) \\
21(61 \cdot 8) \\
29(85 \cdot 3)\end{array}$ \\
\hline $\begin{array}{l}\text { From NoDR to PDR } \\
\text { From NPDR to PDR } \\
\text { Subtotal PDR: }\end{array}$ & $1(12 \cdot 5)$ & $1(10)$ & $\begin{array}{l}1(6 \cdot 25) \\
2(12 \cdot 5)\end{array}$ & $\begin{array}{l}1(2 \cdot 9) \\
4(11 \cdot 8) \\
5(14 \cdot 7)\end{array}$ \\
\hline
\end{tabular}

$\mathrm{ECCE}=$ extracapsular cataract extraction. $\mathrm{IOL}=$ intraocular lens implantation.

ICCE = intracapsular cataract extraction. $D R=$ diabetic retinopathy. NoDR =no diabetic retinopathy $\mathrm{NPDR}=$ non-proliferative diabetic retinopathy. $\mathrm{PDR}=$ proliferative diabetic retinopathy.

Table 3 Progression of diabetic retinopathy during the first year after cataract extraction in relation to surgical technique (numbers of eyes with percentages in parentheses)

\begin{tabular}{lllll}
\hline Follow-up period & $\begin{array}{l}\text { ECCE } \\
(8 \text { eyes })\end{array}$ & $\begin{array}{l}\text { ECCE with IOL } \\
(10 \text { eyes })\end{array}$ & $\begin{array}{l}\text { ICCE } \\
(16 \text { eyes })\end{array}$ & $\begin{array}{c}\text { Total } \\
\text { (34 eyes) }\end{array}$ \\
\hline F1 & $5(62 \cdot 5)$ & $6(60)$ & $7(43 \cdot 75)$ & $18(52 \cdot 9)$ \\
F2 & $2(25)$ & $3(30)$ & $8(50)$ & $13(38 \cdot 2)$ \\
F3 & $1(12 \cdot 5)$ & $1(10)$ & $1(6 \cdot 25)$ & $3(8 \cdot 9)$ \\
\hline
\end{tabular}

$\mathrm{F} 1=$ between 2 weeks and 3 months after surgery. F2=between 4 and 6 months after surgery. F3 = between 7 and 12 months after surgery.

\section{Results}

Of the 89 patients 36 were men and 53 were women. The mean age at the time of surgery was $67 \cdot 1$ years (range 49 to 82 years) and the mean duration of diabetes mellitus was $10 \cdot 1$ years (range 6 months to 30 years). Cataract extraction was unilateral in 68 patients and bilateral in 21 . In the bilateral cases only one eye, the one operated on first, was included in the study. Extracapsular cataract extraction was performed in 12 eyes (13.5\%), ECCE with IOL in 37 $(41 \cdot 5 \%)$, and ICCE in $40(45 \%)$.

During the first postoperative year 55 of the operated eyes $(61.8 \%)$ showed 'no change' in retinal status and $34(38 \cdot 2 \%)$ showed 'progression' of diabetic retinopathy. The corresponding findings in the control group were $87 \cdot 2 \%$ and $12 \cdot 8 \%$ (Table 1 ).

Table 1 compares the clinical features of study patients and controls according to the findings ('no change' or 'progression') during the followup year. Among the operated patients there was no difference between the two subgroups with regard to sex distribution, mean age, mean duration of diabetes mellitus, or the presence of systemic disease. The only significant difference was related to the management of diabetes. Among the operated patients the diabetes was controlled by diet alone more often in patients who showed no change in their retinal status than patients who showed progression of retinopathy, whereas a greater number of patients whose retinopathy progressed needed hypoglycaemic agents and/or insulin for management of diabetes $(\mathrm{p}<0.025)$. A comparison between the clinical features of the study and control groups revealed no significant differences between them (Table 1).

The nature of the postoperative progression of diabetic retinopathy and its relationship to the surgical technique are summarised in Table 2. Of the 34 eyes that showed progression nine $(26.4 \%)$ had no retinopathy prior to surgery but developed it afterwards and the rest $(73.6 \%)$ showed progression of pre-existing retinopathy. The progression in most cases ( 29 eyes or $85.3 \%$ ) took the form of aggravation of non-proliferative changes. However, five eyes $(14 \cdot 7 \%)$ developed PDR. Each of these patterns of postoperative progression of the retinopathy was observed for all three surgical techniques. As can be seen from Table 3, in $91 \%$ of these eyes the changes were 
Table 4 Visual acuity results after cataract surgery in relation to diabetic retinopathy (numbers of eyes with percentages in parentheses)

\begin{tabular}{|c|c|c|c|c|c|c|}
\hline \multirow[b]{2}{*}{$\begin{array}{l}\text { Visual } \\
\text { acuity } \neq\end{array}$} & \multicolumn{3}{|c|}{ No change ${ }^{\star}(n=55$ eyes $)$} & \multicolumn{3}{|c|}{ Progressiont ( $n=34$ eyes) } \\
\hline & $\begin{array}{l}\text { NoDR } \\
(n=38)\end{array}$ & $\begin{array}{l}D R \\
(n=17)\end{array}$ & $\begin{array}{l}\text { Total } \\
(n=55)\end{array}$ & $\begin{array}{l}N o D R \\
(n=9)\end{array}$ & $\begin{array}{l}D R \\
(n=25)\end{array}$ & $\begin{array}{l}\text { Total } \\
(n=34)\end{array}$ \\
\hline $\begin{array}{l}\geq 6 / 12 \\
6 / 15-6 / 30\end{array}$ & $\begin{array}{l}33(87) \\
4(10) \\
1(3)\end{array}$ & $\begin{array}{r}12(70) \\
3(18) \\
2(12)\end{array}$ & $\begin{array}{l}45(82) \\
7(13) \\
3(5)\end{array}$ & $\begin{array}{l}6(67) \\
2(22) \\
1(11)\end{array}$ & $\begin{array}{r}7(28) \\
8(32) \\
10(40)\end{array}$ & $\begin{array}{l}13(38) \\
10(29) \\
11(32)\end{array}$ \\
\hline \multicolumn{7}{|c|}{$\begin{array}{l}\text { ^Without postoperative deterioration of diabetic retinopathy. } \\
\text { tWith postoperative onset of retinopathy, or its deterioration } \\
\text { either to more severe non-proliferative or to proliferative diabetic } \\
\text { retinopathy. } ¥ \text { Visual acuity at final follow-up visit. }\end{array}$} \\
\hline \multicolumn{7}{|c|}{$\begin{array}{l}\text { Table } 5 \text { Postoperative course of diabetic retinopathy in } \\
\text { relation to its preoperative status }\end{array}$} \\
\hline $\begin{array}{l}\text { Preoperative } \\
\text { status }\end{array}$ & $\begin{array}{l}\text { No. of } \\
\text { eyes }\end{array}$ & & $\begin{array}{l}\text { change } \\
=55 \text { eyes }) \\
(\%)\end{array}$ & & $\begin{array}{l}\text { ession } \\
4 \text { eyes) } \\
\%)\end{array}$ & $p$ \\
\hline $\begin{array}{l}\text { NoDR } \\
\text { DR }\end{array}$ & $\begin{array}{l}46 \\
43\end{array}$ & & & & & $\begin{array}{l}<0.005 \\
<0.005\end{array}$ \\
\hline
\end{tabular}

Table 6 Rate of progression of diabetic retinopathy during one year of follow-up after cataract surgery and in controls (present study) and in the general diabetic population (Nielsen's study ${ }^{12} 13$ )

\begin{tabular}{|c|c|c|c|c|}
\hline & & & Nielsen & \\
\hline & Present study & & Nonoperat & \\
\hline & $\begin{array}{l}\text { Operated } \\
\% \quad \text { (No.) }\end{array}$ & $\begin{array}{l}\text { Non- } \\
\text { operatedt } \\
\% \quad(\text { No. })\end{array}$ & $\begin{array}{l}\text { Non- } \\
\text { insulin use } \\
\%\end{array}$ & $\begin{array}{l}\text { Insulin } \\
\text { use } \\
\%\end{array}$ \\
\hline $\begin{array}{l}\text { NoDR } \rightarrow \text { NPDR } \\
\text { NPDR } \rightarrow \text { NPDR } \\
\text { NoDR } \rightarrow \text { PDDPS }\end{array}$ & $\begin{array}{rr}9 \cdot 0 & (8 / 89) \\
23 \cdot 6 & (21 / 89)\end{array}$ & $\begin{array}{ll}4 \cdot 3 & (3 / 70) \\
7 \cdot 1 & (5 / 70)\end{array}$ & $\begin{array}{l}3 \cdot 7 \\
6 \cdot 6\end{array}$ & $\begin{array}{r}3 \cdot 7 \\
10 \cdot 7\end{array}$ \\
\hline $\begin{array}{l}\text { NPDR } \rightarrow \text { PDR } \\
\text { Total }\end{array}$ & $\begin{array}{rr}5 \cdot 6 & (5 / 89) \\
38 \cdot 2 & (34 / 89)\end{array}$ & $\begin{array}{rr}1.4 & (1 / 70) \\
12 \cdot 8 & (9 / 70)\end{array}$ & $\begin{array}{r}1 \cdot 1 \\
11 \cdot 4\end{array}$ & $\begin{array}{r}2.3 \\
16.7\end{array}$ \\
\hline
\end{tabular}

ॠOperated eyes and $\nmid$ non-operated eyes. $¥$ Aggravation of NPDR. SAs for Table 2 .

Table 7 Relationship between the preoperative status of diabetic retinopathy and its postoperative course for the different surgical techniques (numbers of eyes with percentages in parentheses)

\begin{tabular}{|c|c|c|c|c|}
\hline \multirow[b]{2}{*}{$\begin{array}{l}\text { Preoperative } \\
D R\end{array}$} & \multicolumn{2}{|c|}{ ECCE with $I O L$ (37 eyes) } & \multicolumn{2}{|c|}{ ICCE (40 eyes) } \\
\hline & $\begin{array}{l}\text { No change } \\
(n=27)\end{array}$ & $\begin{array}{l}\text { Progress } \\
(n=10)\end{array}$ & $\begin{array}{l}\text { No change } \\
(n=24)\end{array}$ & $\begin{array}{l}\text { Progress } \\
(n=16)\end{array}$ \\
\hline $\begin{array}{l}\text { NoDR }(42) \\
\text { DR (35) } \\
\text { p }\end{array}$ & $\begin{array}{c}24(88 \cdot 8) \\
3(11 \cdot 2) \\
<0\end{array}$ & $\begin{array}{l}3(30) \\
7(70)\end{array}$ & $\begin{array}{l}13(54 \cdot 2) \\
11(45 \cdot 8) \\
<0\end{array}$ & $\begin{array}{r}2(12.5) \\
14(87.5)\end{array}$ \\
\hline
\end{tabular}

already evident within six months of surgery. Moreover, in most of the eyes that underwent ECCE, with or without IOL, the change could already be detected within the first follow-up period - that is, within three months of surgery. By contrast, following ICCE the number of eyes showing the beginning of progression was similar in the first and the second periods of follow-up.

The final visual acuity results are summarised in Table 4. In eyes with no pre-existing retinopathy and no change in postoperative retinal status a visual acuity of at least $6 / 12$ was achieved in $87 \%$ of the cases. By contrast, a relatively high proportion $(40 \%)$ of eyes with pre-existing diabetic retinopathy and postoperative retinal deterioration had poor visual results of $6 / 30$ or less.

The relationships between the preoperative retinal status and the postoperative course of diabetic retinopathy in the operated eyes are presented in Table 5. Eyes with NoDR pre- operatively showed a significantly higher incidence of no change than of progression in their postoperative retinal status. In eyes with preoperative NPDR the opposite was true: their postoperative retinal status showed a significantly higher incidence of progression than no change $(p<0 \cdot 005)$. Table 6 compares the incidence of the various patterns of progression observed one year after cataract surgery in the study group with their corresponding incidence in the control group as well as in other nonoperated groups drawn from the general diabetic population. ${ }^{12} 13$

Since the results presented in Table 5 appear to indicate that the pre-existence of diabetic retinopathy could be considered a risk factor for its postoperative progression, we examined the relationship between the preoperative status of diabetic retinopathy and its postoperative course for each type of surgical technique (Table 7). In analysing this relationship we restricted the comparison to two surgical subgroups, ECCE with IOL and ICCE, since the number of cases in these two subgroups was similar and therefore comparable, while the number in the ECCE without IOL subgroup was small. The results show that, for both techniques, eyes without preexisting diabetic retinopathy tended to remain stable more often than to deteriorate; while eyes with pre-existing NPDR tended to progress more often than to remain unchanged.

\section{Discussion}

The aims of this study were (1) to find out if the eyes of diabetic patients who undergo cataract surgery are more prone than non-operated eyes of diabetic patients to develop or to show progression of diabetic retinopathy; (2) to identify the risk factors for postoperative progression of diabetic retinopathy; and (3) to follow the course of the disease in this particular group of operated patients. To achieve the last objective we attempted to eliminate any factors that might affect the natural course of the disease postoperatively. Accordingly, we excluded from the study group eyes with any additional diseases such as glaucoma or macular diseases other than diabetes, eyes that experienced : operative complications such as vitreous loss or disruption of the posterior lens capsule, or eyes treated by laser photocoagulation before or immediately after surgery for pre-existing PDR or severe NPDR. Thus at the time of surgery the eyes in our study group presented only with NoDR or mild to moderate NPDR.

The differentiation between aphakic or pseudophakic cystoid macular oedema and diabetic cystoid macular oedema is a major problem. ${ }^{3}$ In this series 'progression' of diabetic retinopathy was defined only where worsening of the characteristics typical for diabetic retinopathy were observed, regardless of whether foveal cystoid oedema was present or not. Thus patients with cystoid macular oedema, but with no evidence of other characteristics of diabetic retinopathy, were included in the 'no change' group.

Within 12 months of surgery diabetic retinopathy progressed in $38 \cdot 2 \%$ of eyes that under- 
went cataract extraction as compared with only $12.8 \%$ in non-operated eyes over the same period (Table 6). The incidence of progression of diabetic retinopathy in our control group is in line with that reported by Nielsen, ${ }^{12}{ }^{13}$ who studied the course of diabetic retinopathy over a one-year period in the general diabetic population aged 30 or older at the time of disease onset (Table 6). On the other hand in a four-year study of the incidence and progression of diabetic retinopathy in patients aged at least 30 at the time of disease diagnosis Klein and associates found that worsening of retinopathy occurred in $34 \%$ of those who used insulin and in $25 \%$ of those who did not, while for development of PDR the corresponding rates were $7 \%$ and $2 \% .{ }^{14}$ The relatively high rates of progression of preexisting NPDR and development of PDR found during the first postoperative year in our study group may be comparable to those reported by Klein et al in their four-year study. One could interpret these findings to suggest that the effect of cataract surgery on the progression of preexisting NPDR and development of PDR might be equivalent to the natural course of the disease over four years in non-operated eyes. Since the pre-eminent risk variable for the occurrence of any diabetic retinopathy is thought to be the duration of the disease, ${ }^{15-17}$ this interpretation, even though only speculative, should be kept in mind when planning cataract surgery for diabetic patients.

Klein et al also found a high rate of new onset of retinopathy in patients who had been free of retinopathy at the start of the four-year study. ${ }^{14}$ In contrast, the commonest pattern of progression seen in our study group was worsening of pre-existing NPDR (Table 2). In addition we found that retinal deterioration occurred nearly four times (7/27) as often in eyes with preexisting diabetic retinopathy as without it (Table 5), thus pointing to the pre-existence of diabetic retinopathy as a possible risk factor for its postoperative progression.

The more frequent deterioration of diabetic retinopathy in our study group than in nonoperated eyes of this and of other series 245 appears to support earlier suggestions that removal of the lens may result in a progression of diabetic retinopathy and/or development of rubeosis iridis, ${ }^{18} 19$ in contrast to the findings reported by Sebestyen, ${ }^{7}$ who observed similar progression of retinopathy in operated and nonoperated eyes. It is not yet clear how the removal of the lens may affect diabetic retinal changes in general. However, with regard to one specific characteristic of diabetic retinopathy - the occurrence of endothelial proliferation and neovascularisation - Williams et $a l^{20}$ showed that human lens extracts can inhibit endothelial proliferation. Therefore their removal may induce vascular alterations resulting in neovascularisation. Furthermore they also demonstrated considerable inhibition of endothelial cell activity in extracts of bovine lens capsule, ${ }^{20}$ and suggested that the presence of an intact lens capsule may inhibit the development of iris neovascularisation. Clinical experience seems to support these findings.
Aiello et $a l^{18}$ found that, following ICCE, patients with or without background retinopathy were at particularly high risk of developing vitreous haemorrhage, presumably reflecting progression of the disease to PDR. Alpar ${ }^{56}$ observed deterioration of diabetic retinopathy in some diabetic patients following either ICCE or ECCE, with the least progression occurring in patients who underwent ECCE with IOL implantation in the capsular bag. In the present study we also found progression of diabetic retinopathy following both procedures, with a lower incidence in cases of ECCE with IOL (10 out of 27 eyes, 37\%) than in ICCE (16 out of 40 eyes, 40\%) (Table 7). However, this finding could be explained at least partially by the lower proportion of eyes at risk because of pre-existing NPDR in the group undergoing ECCE with IOL $(27 \%, 10$ out of 37 eyes) than in the ICCE group $(62.5 \%, 25$ out of 40 eyes) (Table 7$)$. Although clinical evidence suggests that ICCE may have a more deleterious effect than ECCE on the postoperative course of diabetic retinopathy, the precise role of the posterior lens capsule in reducing vascular complications after cataract surgery in diabetic patients requires further investigation.

Of the 34 eyes in our study that showed postoperative retinal deterioration the majority $(85 \cdot 3 \%)$ did not progress to PDR but remained at the non-proliferative stage, sometimes with postoperative macular oedema, which affected the final visual results. The visual outcome following cataract surgery in our study (Table 4) was especially poor in patients with pre-existing diabetic retinopathy who showed postoperative progression; it should however be noted that in the progression subgroup, good visual acuity was achieved in $67 \%$ of eyes with preoperative NoDR and in $28 \%$ of eyes with preoperative NPDR. The largest subgroup (87\%) to achieve good visual results consisted of patients with no preexisting diabetic retinopathy and no change postoperatively.

The only significant difference in general clinical conditions between patients with no change in retinal status and patients with postoperative progression of diabetic retinopathy related to the management of diabetes: more patients in the 'no change' group than in the 'progression' group were managed by dietary control alone (Table 1).

The results of this study clearly indicate that progression of diabetic retinopathy is not uncommon after cataract surgery, even when the technique employed is ECCE. Patients with diabetic retinopathy prior to surgery are at higher risk for progression. Accordingly these patients should be closely monitored postoperatively for early signs of progression of diabetic retinopathy and where necessary should be considered candidates for laser treatment. Diabetic patients scheduled for cataract extraction should be informed that surgery may have an adverse influence on diabetic retinopathy and that this may affect the final visual outcome. The preoperative status of diabetic retinopathy may be a significant prognostic factor for the postoperative outcome. 
1 Straatsma BR, Pettit TH, Wheeler N, Miyamasu W. Diabetes mellitus and intraocular lens implantation. Ophthalmology 1983; 90: 336-43.

2 Jaffe GJ, Burton TC. Progression of nonproliferative diabetic retinopathy following cataract extraction. Arch Ophthalmol 1988; 106: 745-9.

3 Pollack A, Dotan S, Oliver M. The course of diabetic retinopathy following cataract surgery. $\mathrm{Br} \mathrm{J}$ Ophthalmol 1991; 75: 2-8.

4 Apple DJ, Mamalis N, Loftfield K, et al. Complications of intraocular lenses. A historical and histopathological review. Surv Ophthalmol 1984; 29: 1-54.

5 Alpar JJ. Cataract extraction and diabetic retinopathy. $f \mathrm{Am}$ Intraocul Implant Soc 1984; 10: 433-7.

6 Alpar JJ. Diabetes, cataract extraction and intraocular lenses. $\mathcal{f}$ Cataract Refract Surg 1987; 13: 43-6.

7 Sebastyen JG. Intraocular lenses and diabetes mellitus. $A m \mathcal{F}$ Ophthalmol 1986; 101: 425-8.

8 Rubinstein K, Myska V. Pathogenesis and treatment of diabetic maculopathy. Brf Ophthalmol 1974; 58: 76-84.

9 Merin S, Yanko L, Ivry M. Treatment of diabetic maculopathy by by argon-laser. $\mathrm{Br} \mathcal{F}$ Ophthalmol 1974; 58: 85-91.

10 Blankenship GW. Diabetic macular edema and argon laser photocoagulation: a prospective randomized study. Ophthalmolog 1979; 86: 69-75.

11 Schatz H, Patz A. Cystoid maculopathy in diabetics. Arch Ophthalmol 1976; 94: 761-8.

12 Nielsen NV. Diabetic retinopathy. II. The course of retinopathy in diabetics treated with oral hypoglycaemic agent and diet regime alone. A one year epidemiological cohor study of diabetes mellitus. The Island of Falster, Denmark. Acta Ophthalmol (Kbh) 1984; 62: 266-73.
13 Nielsen NV. Diabetic retinopathy. I. The course of retinopathy in insulin-treated diabetics. A one year epidemiological cohort study of diabetes mellitus. The Island of Falster, Denmark. Acta Ophthalmol (Kbh) 1984; 62: 256-

14 Klein R, Klein BEK, Moss SE, Davis MD, DeMets DL. The Wisconsin Epidemiologic Study of Diabetic Retinopathy. Four-year incidence and progression of diabetic retinopathy when age at diagnosis is 30 years or more. Arch Ophthalmol

15 Klein R, Klein BEK, Moss SE, Davis MD, DeMets DL. The Wisconsin Epidemiologic Study of Diabetic Retinopathy: II. Prevalence and risk of diabetic retinopathy when age at diagnosis is less than 30 years. Arch Ophthalmol 1984; 102: $520-6$.

16 Klein R, Klein BEK, Moss SE, Davis MD, DeMets DL. The Wisconsin Epidemiologic Study of Diabetic Retinopathy. III. Prevalence and risk of diabetic retinopathy when age at diagnosis is 30 or more years. Arch Ophthalmol 1984; 102: $527-32$.

17 Burditt AF, Caird FI, Draper GJ. The natural history of diabetic retinopathy. Q7 Med 1967; 37: 303-17.

18 Aiello LM, Wand M, Liang G. Neovascular glaucoma and vitreous hemorrhage following cataract surgery in patients with diabetes mellitus. Ophthalmology 1983; 90: 814-20.

19 Poliner LS, Christianson DJ, Escoffery RF, Kolker AE, Gordon ME. Neovascular glaucoma after intracapsular and extracapsular cataract extraction in diabetic patients. $A m \mathcal{F}$ Ophthalmol 1985; 100: 637-43.

20 Williams GA, Eisenstein R, Schumacher B, Hsiao KC, Grant $D$. Inhibitor of vascular endothelial cell growth in the lens. Am f Ophthalmol 1984; 97: 366-71. 